\title{
$\mathrm{Nd}$ 系超電導体のプロセス研究の動向
}

\author{
塩原融 \\ (財) 国際超電導産業技術研究センター, 超電導工学研究所, $\bar{\top}$ 135-0045 江東区東雲 1-10-13.
}

\section{Trend of Processing Research of Nd-system Superconductive Oxides}

\author{
Yuh Shiohara \\ Superconductivity Research Laboratory, International Superconductivity Technology Center, 1-10-13 Shinonome Koto-ku, Tokyo $135-0045$.
}

Received September 29, 1997

\section{SYNOPSIS}

Single crystal growth and solidification processing of Nd-123 superconductive oxides are reviewed in comparison with Y-123 oxide. Since Nd-123 crystal forms a solid solution due to $\mathrm{Nd} / \mathrm{Ba}$ substitution, this crystal is considered to be nonstoichiometric while $\mathrm{Y}-123$ is a stoichiometric compound at least for its cation constituents. Crystal growth processing of nonstoichiometric compounds (Nd-123) with homogeneous composition distribution should be different from that of stoichiometric (Y-123) compounds, because the former case is one degree of freedom in the Gibbs phase rule higher than the latter case. In this paper, difference in crystal growth mechanisms between Nd-123 and Y-123 is discussed, taking into consideration of equilibrium phase diagrams, kinetics of the 123 phase crystal growth.

\section{KEY WORDS}

superconductive oxides, $\mathrm{RE}(\mathrm{Nd}$ or $\mathrm{Y}) \mathrm{Ba}_{2} \mathrm{Cu}_{3} \mathrm{O}_{6+\delta}$, nonstoichiometric compounds, single crystal growth, peritectic solidification

\section{1 緒言}

酸化物系高温超電導材料が発見されて以来 10 年が過ぎ, 物 性研究に並行して応用基礎研究が大いに進展した.特に液体窒 素温度 $(77 \mathrm{~K})$ 以上の臨界温度を有し, 且つ77K 磁場中臨界電流 密度が $10^{5} \mathrm{~A} / \mathrm{cm}^{2}$ を越之得る材料としての RE123系超電導材料 のプロセス研究の進展は著しい. RE123材料のプロセスとして は, 高緻密性, 単相化, 配向性制御, 粒界弱結合の除去, ピン ニングセンター導入等の高臨界電流密度化に不可欠な主要素を 満足し, 且つ凝固晶出温度が約 $1000^{\circ} \mathrm{C}$ と低いことから溶融凝固 プロセスの研究が精力的に進められてきている。本報では Y123 系材料の凝固結晶成長機構を 123 相単結晶成長の実験結 果で解説するとともに, 高臨界温度 $(\sim 96 \mathrm{~K})$ が確認され, 且つ 高磁場下での高臨界電流密度が達成されているNd123材料の単 結晶成長を Y 123 材料と対比させ, 平衡状態図に基づいた結晶 成長速度論でその成長機構及び特性を解説する。

\section{2 高温相平衡状態図}

材料の相平衡状態図の知見は種々の環境条件下に括ける相安 定を論ずる以外にも, 結晶成長機構を理解する上にも必要不可
久である.超電導酸化物材料に関しての平衡状態図の研究は, 発見以来主として超電導特性評価温度近傍の極低温あるいは発 見当初沉用された粉末焼結・酸素熱処理プロセス温度 $(300$ 一 $800^{\circ} \mathrm{C}$ ) に対しての研究が進められてきた。特に，溶融凝固プロ 七ス時の結晶成長を論ずる際には液相を含んだ詳細な高温平衡 状態図が重要であるが, 殆ど報告されていない。ここでは, 液 相からの結晶成長に重要なREBCO擬二元系平衡状態図の一部 である Y, Sm, Nd の液相中溶解度を Fig. 1 に示すり。図より 123 相はインコングルエントメルト酸化物であり, 約 $1000^{\circ} \mathrm{C} て ゙$ 高温 安定相の 211 相と液相との包晶反応で晶出することが理解でき る.また, 液相中の $\mathrm{Y}_{2} \mathrm{O}_{3}$ 成分の溶解度は $0.6 \%$ と低く，コらに 液相線勾配も急峻であることが特徵である。このことは，とも に液相中物質移動速度を考慮すると液相からの結晶成長速度を 速くすることを困難にしており，現実に大きな結晶が得られて いない一因と考えられる. RE元素を $\mathrm{Sm}, \mathrm{Nd}$ に置き換えると包 晶温度, 溶解度ともに上昇し, 液相線勾配は低下することが認 められる。このことから, $\mathrm{Sm}, \mathrm{Nd}$ 系単結晶の成長速度は速くな る. Fig. 2 に包晶温度近傍における擬三元系等温平衡状態図の CuO-rich 近傍の一部を $\mathrm{YBCO}$ 系 $^{21}$ (大気中) 及び $\mathrm{NdBCO}$ 系 ${ }^{3.4}$ ) 


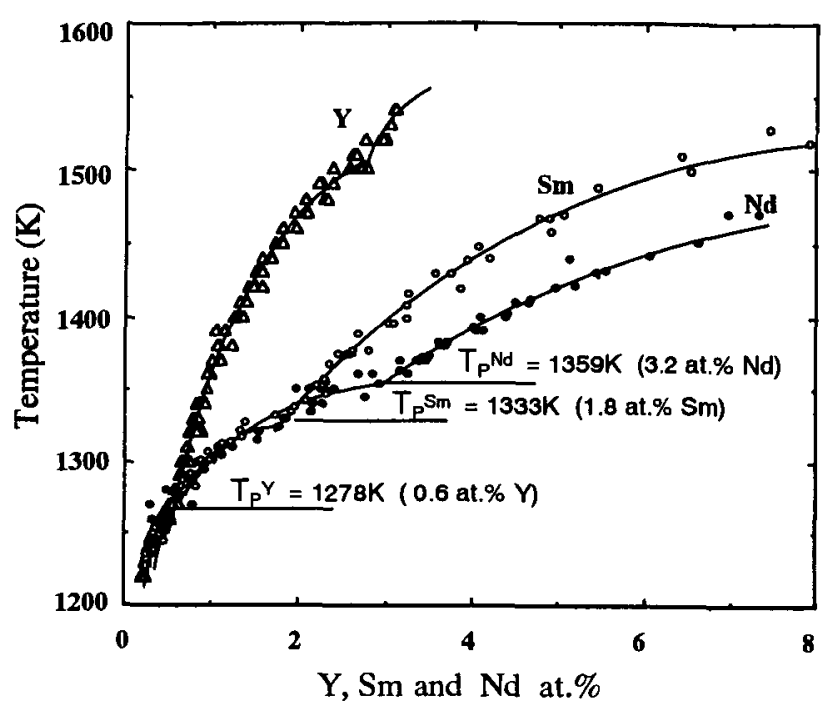

Fig.1 Temperature dependence of $\mathrm{Y}, \mathrm{Sm}$ and $\mathrm{Nd}$ solubility in $\mathrm{Ba}_{3} \mathrm{Cu}_{5} \mathrm{O}_{8}$ solvent.

$\left(\mathrm{PO}_{2}=0.01 \mathrm{~atm}\right.$ 及び大気中) を対比して示す．低酸素分圧下の $\mathrm{Nd}$ 系平衡状態図は大気雲囲気下のY系状態図と定性的に同様 であり, 液相組成の変化に拘わらず固相 123 相組成は化学量 論組成比で一定であるが, 大気雾囲気下のNd系状態図では固 相 123 相は $\mathrm{Nd} / \mathrm{Ba}$ が置換した固溶体組成を取り，その組成は 液相組成に依存し，等化学ポテンシャルタイラインで結ばれ ている.超電導臨界温度は結晶の組成に敏感であることから， 123化学量論組成比を有する結晶を得るには大気雾囲気下結晶 成長ではY系に比して，Nd系では制御因子が増えることにな り, 成長温度, 成長界面液相組成を一定にした定常成長が必 要となる。この固溶体形成の傾向はSm系も同様に起こる.

\section{Y123単結晶育成と超電導特性}

大型高品質超電導単結晶を引き上げ法により育成する方法 の開発に成功した ${ }^{3)}$. Fig.3に SRL-CP(Solute Rich Liquid Crystal

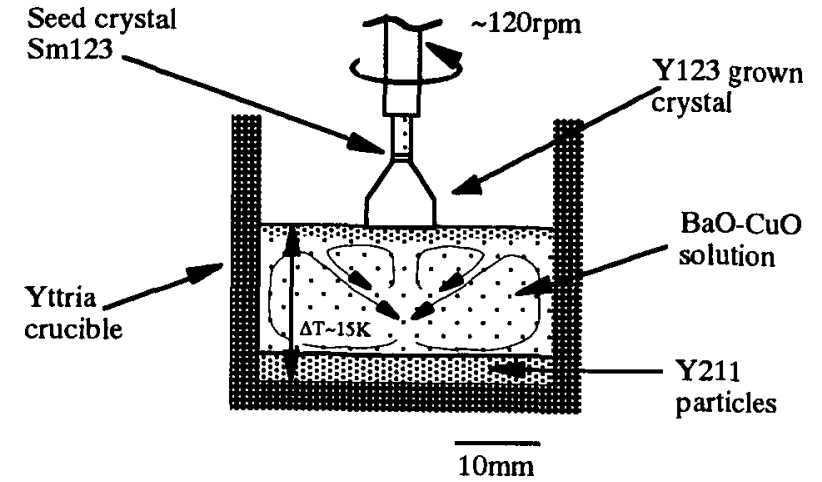

Fig.3 Schamatic illustration of experimental set-up for Y123 single crystal pulling by the SRL-Cp method.

Pulling)法によりY系単結晶育成時の坩堝内構成の概略図を示 す、イットリア製坩堝の底に固体のY 211 粉末層を形成し, 溶 媒となる $\mathrm{BaO}-\mathrm{CuO}$ 酸化物フラックスをその上部に挿入する。 溶媒を融解させた後，坩堝内に温度勾配を設定し，表面温度 を包晶温度以下，底部を包晶温度以上に維持する。液表面に 種結晶を接触させ，回転させつつ低速で引き上げを実施し， 単結晶を連続育成させる. 坩堝底部においては固相のY211と 平衡するY-rich な液相が存在し, 負の温度勾配に起因した自 然対流と結晶回転による強制対流により液面に輸送され, 結 晶成長界面は溶質富化溶液となり, その温度が包晶温度以下 であるため，Y123相単結晶が種結晶上に成長する。この時の 結晶成長方位は種結晶の方位で制御される。通常, 結晶の高 品質性を維持させる目的から，低速ではあるが，C蟿方向に 単結晶を引き上げる. Fig.4に典型的な約 $15 \mathrm{~mm}$ 角の引き上げ Y123単結晶外観写真を示す, 単結晶引き上げ底部はX-線ラ ウエ回析から(001)面であり，種結晶からエピタキシャル成長 していることが確認されている。また，結晶成長表面の AFM(Atomic Force Microscopy) 観察から，Fig.5のようにC軸 一格子長のステップを有した連続スパイラル成長で結晶成長 (a)

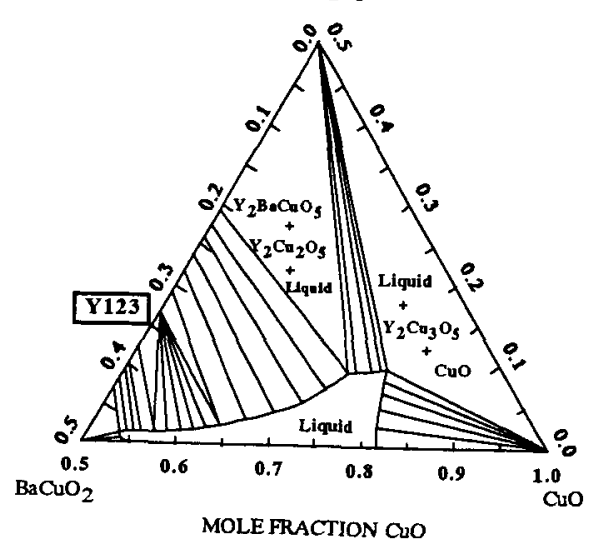

(b)

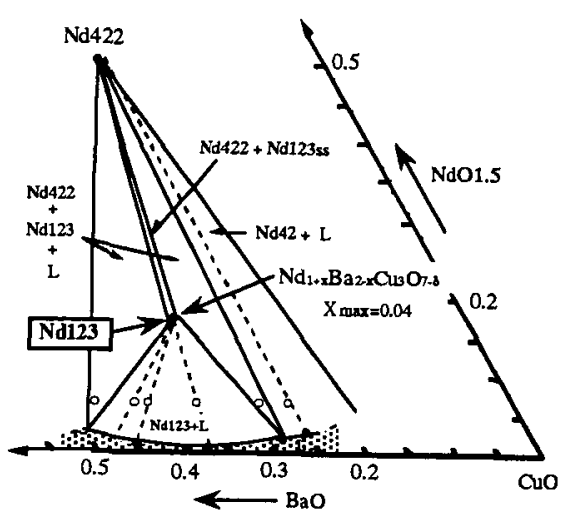

(c)

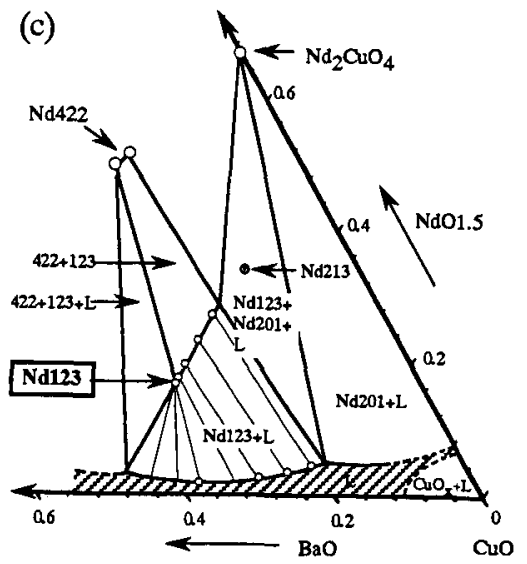

Fig.2 Quasi-Ternary isothermal equilibrium phase diagrams of REBCO system in the CuO-rich corner near the peritectic temperature. (a) YBCO: in the air atmosphere, (b) $\mathrm{NdBCO}: \mathrm{PO}_{2}=0.01 \mathrm{~atm},(\mathrm{c}) \mathrm{NdBCO} *$ in the air atmosphere. 

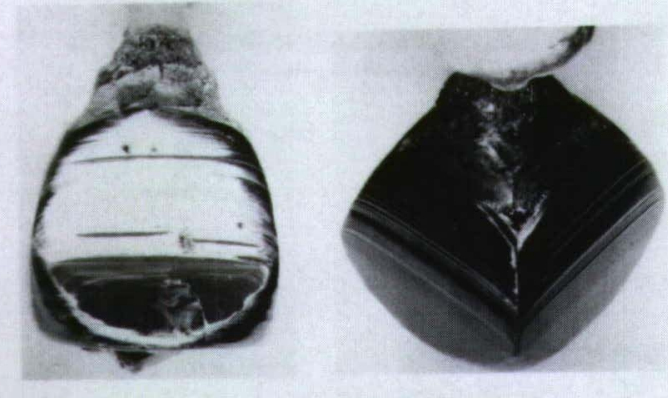

$10 \mathrm{~mm}$

Y123 single crystal grown along the c-axis

Fig.4 Photographs of $15 \mathrm{~mm}$ squared Y123 single crystal
が進行していると考えられる. 得られた単結晶から試料を切 り出し, $400^{\circ} \mathrm{C} 2$ ケ月の純酸素気流中熱処理後, 直流 4 端子法 の抵抗測定から超電導臨界温度を (001) 面および (100) 面で 行った結果を Fig.6に示す. 両面ともに $92 \mathrm{~K}$ の臨界温度を示し ている.

\section{$4 \mathrm{Nd} 123$ 単結晶育成と超電道特性}

Nd123単結晶の育成方法は基本的にはY123単結晶育成と同 様であるが，前述の平衡状態図の項で概説したように，包晶 温度, 溶解度ともに上昇し, 液相線勾配は低下することから, $\mathrm{Sm}, \mathrm{Nd}$ 系単結晶の成長速度は速くなる. 123 化学量論組成の 単結晶育成には雾囲気の酸素分圧を低くすること，あるいは 溶媒である $\mathrm{BaO}-\mathrm{CuO}$ 組成比を $\mathrm{BaO}-$ richにすることが重要であ る. Fig.7 に溶媒組成を $\mathrm{BaO} / \mathrm{CuO}=3 / 5$ と一定にして, 雾囲気酸 素分圧を変化させて育成した Nd123単結晶の磁化特性を示す ${ }^{6}$. 雲囲気酸素分圧の低下とともに超電導臨界温度が上昇すると

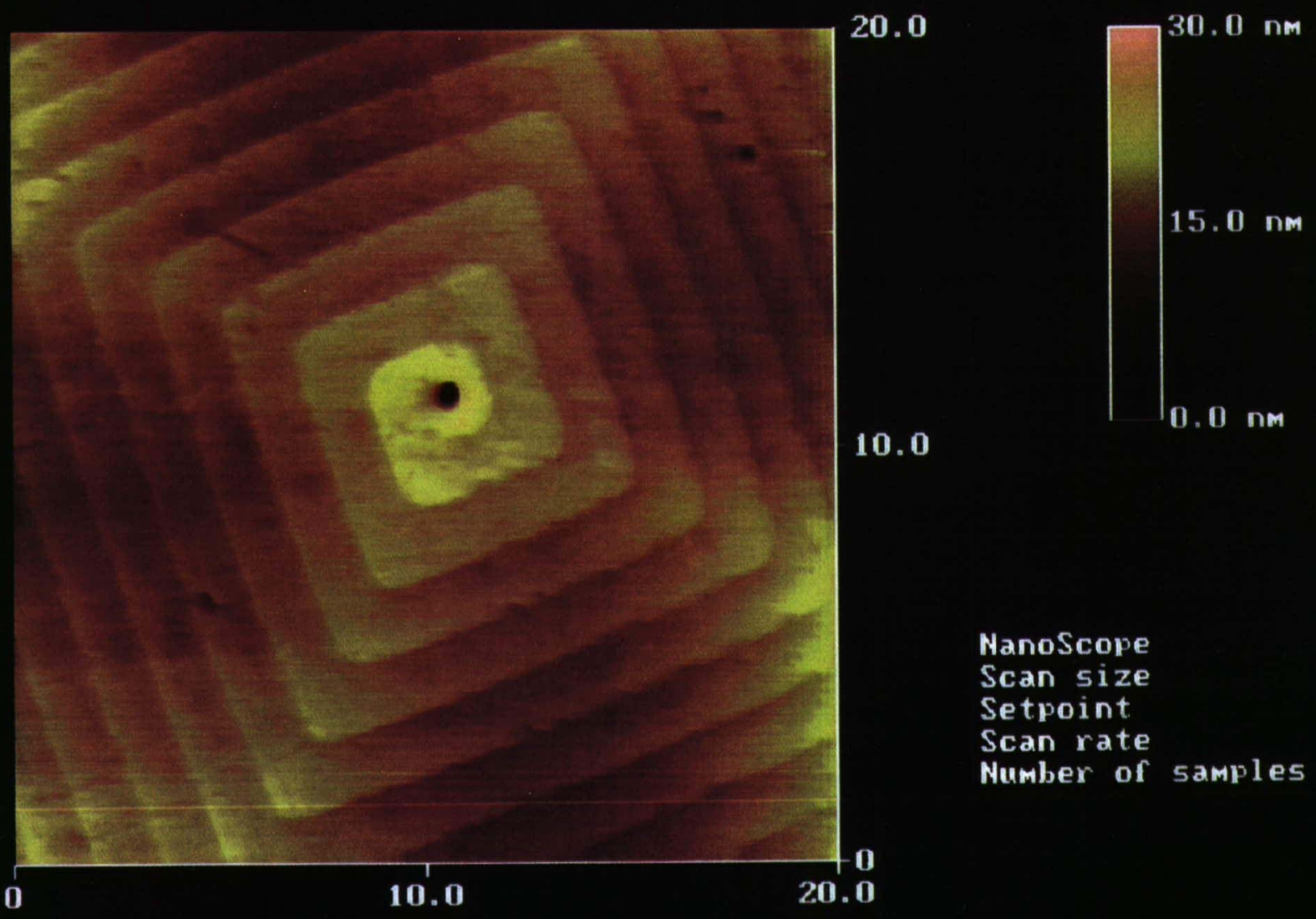



yao-yzn . p20

Fig.5 Spiral growth pattern image at the growth surface of Y123 single crystal observed by AFM 


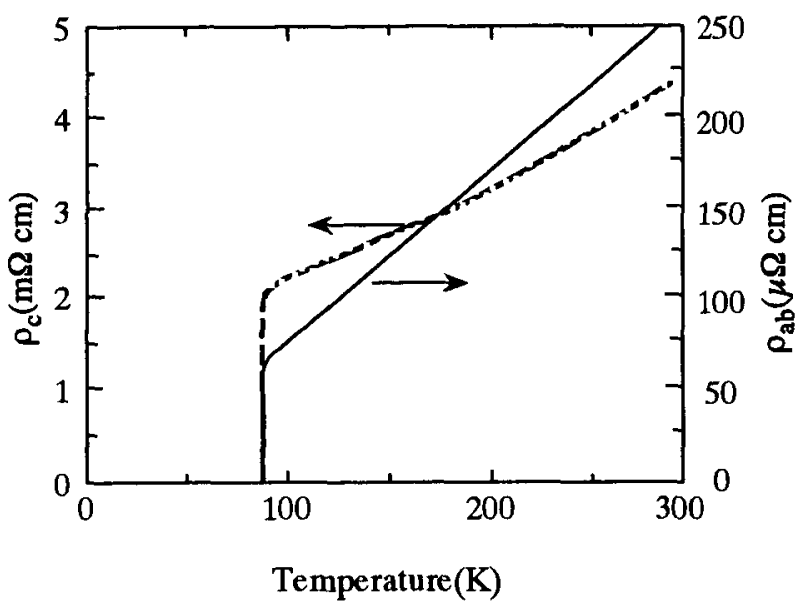

Fig.6 Temperature dependence of resistivities along the c-axis and in the ab plane of Y123 single crystal after oxygen gas annealing.

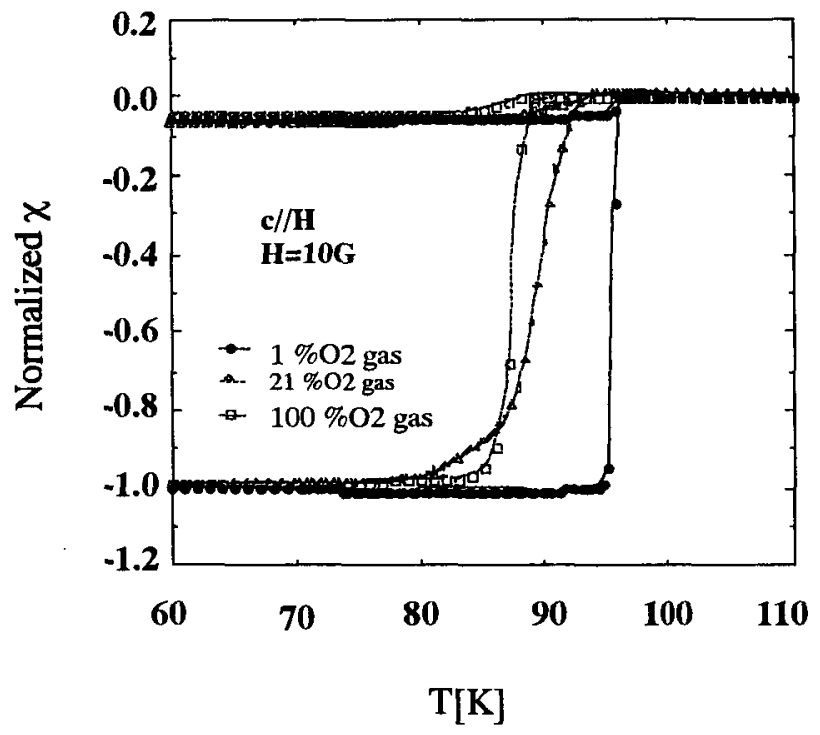

Fig.7 Effect of oxygen partial pressure of the atmosphere during crystal growth on magnetization properties for $\mathrm{Nd} 123$ single crystals.

ともに転移温度幅も小さくなり，超電導特性ならびに結晶性 が向上していることが分かる。このことは，前述の平衡状態 図から認められるように，低酸素分圧下では $\mathrm{Nd} / \mathrm{Ba}$ 置換によ る固溶体の固溶限が小さくなり，ほほ 123 組成の均一な単結 晶が有成されるためと考えられる. Fig.8に溶媒組成比 $(\mathrm{BaO} /$ $\mathrm{CuO})$ を $0.61 \sim 0.85$ と変化させて育成した単結晶の磁化特性を 示す7， $\mathrm{BaO} / \mathrm{CuO}$ 比を高くすることにより，超電導臨界温度 が上昇するとともに転移温度幅も小さくなり，超電導特性が 向上していることが分かる.このことは，得られた固溶体単 結晶の組成分析をICPで行い，溶液組成と対応させたFig.9に 示す関係から説明出来る。高 $\mathrm{BaO} / \mathrm{CuO}$ 比の溶液に平衡する固 溶体組成が 123 組成比に近いことから，低BaO/CuO比ほどNd/ Ba置換が大きくなり，超電導転移温度が低下寸るものと考え られる。

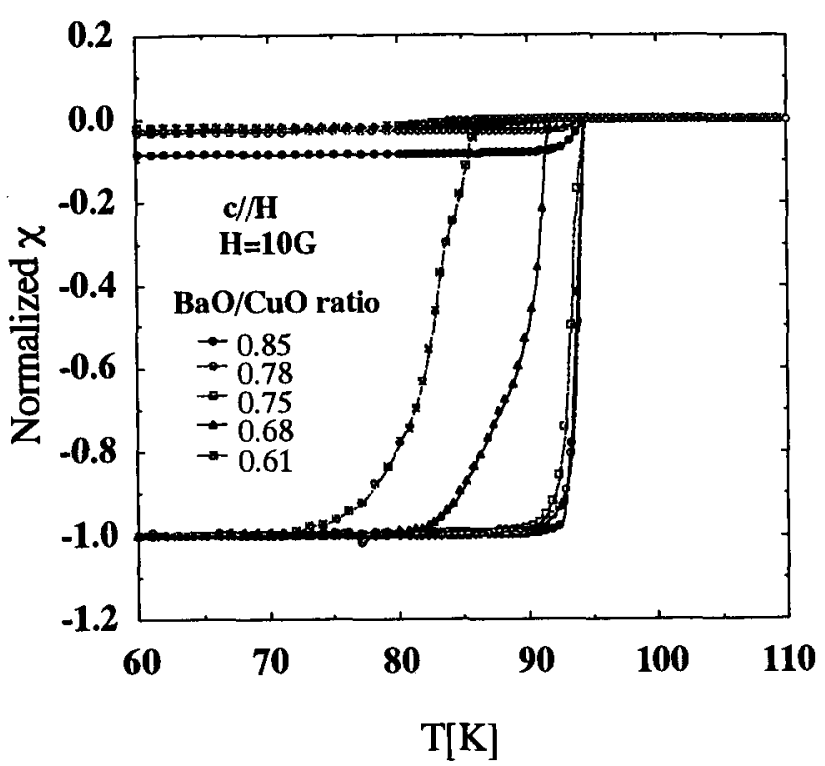

Fig.8 Effect of $\mathrm{BaO} / \mathrm{CuO}$ ratio of the solvent during crystal growth on magnetization properties for $\mathrm{Nd} 123$ single crystals.

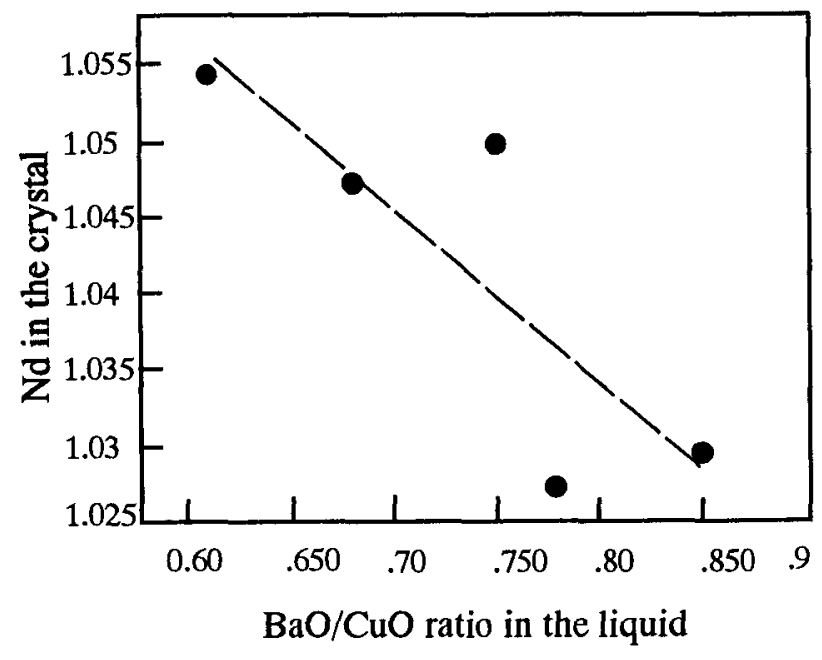

Fig.9 Effect of $\mathrm{BaO} / \mathrm{CuO}$ ratio of the solvent during crystal growth on Nd contents in the grown Nd123 single crystals.

\section{5 結 言}

超電導結晶として代表的な RE123単結晶育成時の結晶成長 機構を平衡状態図を使用して解説するとともに，特に $\mathrm{Nd} 123$ 結晶成長条件と超電導特性との相関を実験結果と対比させた。 尚，本研究は産業科学技術研究開発制度の一環として，新工 ネルギー産業技術開発機構から委託を受けて実施したもので ある。

\section{文献}

1) Ch.Krauns, M.Sumida, M.Tagami, Y.Yamada and Y.Shiohara, Z. Phys. B, 96(1994)207.

2) B.J.Lee and D.N.Lee, J. Am. Ceram. Soc., 74(1991)78.

3) M.Yoshizumi, M.Kambara, Y.Shiohara and T.Umeda, Extended Abstract of ' 97 International Workshop on Superconductivity 
'The 3rd. Joint ISTEC/MRS Workshop), 295.

4) M.Kambara, M.Tagami, X.Yao, E.A.Goodlin, Y.Shiohara and T.Umeda, submitted to J. Am. Ceram. Soc. for publication.

5) Y.shiohara and A.Endo, Matyerials Science and Engineering, R19(1997)1.
6) M.Nakamura, H.Kutami and Y.Shiohara, Physica C, 260(1996)297.

7) X.Yao, M.Kambara, T.Umeda and Y.Shiohara, Extended Abstract of ' 97 International Workshop on Superconductivity 'The 3rd. Joint ISTEC/MRS Workshop), 291. 